\title{
Role of topical application of gentamicin containing collagen implants in cardiac surgery
}

\author{
Pankaj Kumar Mishra ${ }^{1 *}$, Ahmed Ashoub², Kareem Salhiyyah², Dincer Aktuerk', Sunil Ohri², Shahzad G Raja ${ }^{3}$ \\ and Heyman Luckraz'
}

\begin{abstract}
Sternal wound infections (SWI) continue to be a major cause of concern after cardiac surgery. It leads to prolonged hospital stay and increased morbidity, mortality and increased hospital costs. Prophylactic systemic antibiotics have been used to prevent surgical site infection (SSI). However, prolonged postoperative use of systemic antibiotics can lead to emergence of resistant organisms. Gentamycin Containing Collagen Implants (GCCI) when used during sternotomy closure produces high local antibiotic concentrations in the wound with a low serum concentration. There is evidence that the concentration of gentamicin in the mediastinal fluid reaches levels high enough to be effective against bacteria that are considered resistant to gentamycin and other antibiotics.

However, questions have been raised about the safety and efficacy of GCCl. There were concerns whether $\mathrm{GCCl}$ can lead to systemic absorption with renal impairment and whether use of topical antibiotics can lead to emergence of antimicrobial resistance.

We, hereby, review the literature on GCCI (Collatamp) and take the opportunity to appraise the scientific community about their role in cardiac surgery. Several recent studies have supported their clinical effectiveness. They should be used in dry condition and should not be soaked in saline even for a short period prior to use. However, for GCCl to become part of routine practice in cardiac surgery further large randomised studies are required. As the incidence of sternal wound infection is low in the specialty of cardiac surgery, for any study to be sufficiently powered to address this issue, multicenter studies might be the way forward.

Based on the evidence presented in this manuscript it is recommended GCCI (Collatamp) can be a cost effective adjunct for prevention of sternal wound infection. They can also be used for treatment of Deep Sternal Wound Infection.
\end{abstract}

Keywords: Surgical site infection, Supercial sternal wound infection, Deep sternal wound infection, Mediastinitis, Topical gentamicin, Gentamycin containing collagen implants, Collatamp

\section{Review}

Surgical Site Infections (SSI) is associated with increased length of hospital stay and cost of care [1]. Sternal wound infection (SWI) after cardiac surgery continues to be one of the most serious postoperative complications [2-6]. Superficial Sternal Wound infection (SSWI) leads to increased morbidity while Deep Sternal Wound Infection (DSWI) after cardiac surgery is a serious complication causing substantial increase in both morbidity and mortality. Efforts have been made to decrease the incidence to SWI. However, despite all efforts, DSWI

\footnotetext{
*Correspondence: mishrapk_25@yahoo.com

${ }^{1}$ Cardiothoracic Unit, Heart and Lung Centre, Wednesfield Road, Wolverhampton WV10 0QP, UK

Full list of author information is available at the end of the article
}

is an everyday challenge in the life of a cardiothoracic surgeon.

In the last decade, new ways have been investigated to reduce the incidence of SSWI and DSWI. After positive experience in other specialties (e.g. colorectal surgery, orthopaedics) with topical antibiotic preparations, resorbable gentamicin-containing collagen implant (GCCI) has been introduced in cardiac surgery in an effort to reduce the incidence of sternal wound complications [7-9].

Gentamicin Containing Collagen Implant (GCCI) delivers high local concentrations of gentamicin with low serum levels [2-4]. The high local antibiotic concentrations may have an effect on bacteria that are normally considered to be resistant $[2,10]$. Although gentamicin is generally used for gram-negative infections, it does have a spectrum of 
bactericidal activity for many gram-positive organisms, including staphylococci [11].

Gentamicin Containing Collagen Implant (GCCI) are licensed for use in cardiac surgery in over 50 countries but their effectiveness at preventing sternal wound infections (SWIs) continues to be debated [1,2,12]. We hereby, review the published clinical data for prophylactic application of resorbable GCCI following cardiac surgery. We take the opportunity to appraise the scientific community about the safety and efficacy of GCCI in prevention of postoperative sternal wound complication.

\section{Definition and classification of SSI}

The criteria for definition and classification of Surgical Site Infections (SSI) in the literature vary. A majority of studies have used criteria laid down by Centers of Disease Control and prevention for surgical site infection $[2,13,14]$. It is focused on the depth, but not on the clinical severity, of the infection [13]. In UK NICE (National Institute of Clinical Excellence) has issued guidelines for recognition and management of SSI [15]. Deep SWI includes all SWI with sternal dehiscence or infections down to the sternum, even when the sternum remained stable [2,13]. Infections are usually classified as definite if both clinical signs of infection and prespecified bacterial cultures were positive $[1,2,13]$. A more comprehensive clinical wound scoring system, such as the ASEPSIS score will be more informative but more laborious to use [16,17].

\section{Pathophysiology of Sternal Wound Infection (SWI) Incidence and Risk factors}

The reported incidence of postoperative SWI varies considerably; because of differences in definitions and classification of infections and variations in follow-up $[2,18-27]$. Sternal wound infection (SWI) has a reported overall incidence between $0.5 \%$ and $6 \%$ [1]. However, in high-risk patients the incidence has been estimated at between 12 and $20 \%$ with an associated mortality rate between $14 \%$ and $47 \%$ [7,18-22]. Schersten et al. suggest that the incidence of SSI goes higher in studies reporting surgery on high-risk patients and also in patients undergoing emergency operations [28].

Sternal wound infections can be divided into superficial and deep infections (DSWI) [23]. Sternal infections can also be classified as early and late $[23,26]$. Late infections include osteomyelitis, subcutaneous abscess, sterno-cutaneous fistulas and mediastinitis [23]. In cardiac surgery, numerous risk factors for SSI exist, such as obesity, diabetes, COPD, re-operation, use of two internal mammary arteries, and duration of surgery [7,25,29-32]. In the presence of bacterial contamination a slight instability in an osteal fixation promotes the development of clinical infection [33,34].

\section{Bacteriology}

The most common bacteria involved in postoperative wound infections are Gram-positive cocci, mainly staphylococci- either coagulase-negative staphylococci (CoNS) or Staphylococcus aureus [35-37].

Coagulase-negative staphylococci (CoNS) (usually S. epidermidis) have become the most common cause of SWI in many of the reported series [33]. CoNS were also the most commonly present agent in cases with multiple bacterial agents [33-35]. 80\% were resistant to aminoglycosides and $81 \%$ were resistant to methicillin [33]. CoNS often cause chronic infections by forming a biofilm through attachment to an implanted device such as steel wires following median sternotomy [38]. Other organisms e.g. Streptococci, Gram-negative bacteria and fungi, especially Candida albicans, can also cause SWI $[39,40]$.

\section{Prevention of DSWI}

Techniques to decrease SSI include preoperative skin care, aseptic surgical technique, gentle tissue handling and perioperative antibiotic cover [41-43]. Intravenous (IV) antibiotic prophylaxis for median sternotomy has been clearly shown to reduce the wound infection rate in several studies and is a routine practice in most cardiothoracic units [27]. There is some evidence that rigid sternal fixation with, usage of seven or more single sternal fixation wires leads to a lower rate of SWI, compared with only six single wires $[33,44]$.

\section{Topical antibiotics and GCCI}

Gentamicin is predominantly used for gram-negative infections. However, it does have a spectrum of bactericidal activity for many gram-positive organisms, including staphylococci [2,45-48]. Administration of systemic antibiotics may lead to a greater risk of antibiotic resistance [46-48]. The emergence of local antibiotic-eluting products such as resorbable gentamicin-containing collagen implant (GCCI) enables delivery of high local concentrations of gentamicin with corresponding low serum levels. The use of collagen as a carrier also has a positive effect on wound healing [33].

GCCI sponges were introduced in 1985 for the prevention of surgical site infection and they were mainly used after laparotomy [49]. GCCI can be an effective adjunct in reducing the rate of SSI following cardiac surgery particularly in high risk patients [50]. GCCI may also have a role to play in the treatment of established DSWI [51]. However, currently there is no consensus about their use in patients undergoing cardiac surgery [49].

\section{Collatamp}

Collatamp ${ }^{\oplus}$ (Collatamp ${ }^{\oplus}$ G EUSA Pharma Europe) is a lyophilised collagen delivery system for gentamicin, used 
in the prevention and treatment of SSI [52]. Bovine collagen is rapidly absorbed and is an efficient vehicle for local antibiotics delivery. The implants are degraded by collagenases, and do not need to be surgically removed [53]. Collatamp ${ }^{\oplus}$ delivers a high dose of gentamicin, the level and speed of which is dependent on the local blood flow at the site of the wound [54]. The antibiotic is concentrated locally in the tissue and does not reach significant serum levels, which reduces the risk of systemic side effects (ototoxicity/nephrotoxicity) [54]. Collatamp ${ }^{\circ}$ also accelerates haemostasis and positively influences wound healing $[53,54]$. There is evidence that the concentration of gentamicin in the mediastinal fluid reaches levels high enough to be effective against bacteria that are normally considered resistant (including most CoNS) $[2,10,51]$.

\section{Mechanism of action and pharmacokinetics}

Synthetic collagen-based products have been used for their angiogenic properties and their role as a matrix or "scaffold" to promote fibroblast migration and granulation tissue formation [55-59]. Collatamp helps local haemostasis and has been advocated for use in areas with seeping haemorrhage with a high risk of infection. Haemostasis is triggered when blood comes into contact with exposed endogenous collagen fibrils or renatured collagen fibrils like those in Collatamp. The adhesion and aggregation of platelets is induced on the collagen fibrils of Collatamp and the coagulation process is accelerated. The sponge-like structure of Collatamp stabilises the wound clot and also promotes granulation and epithelialisation. Overall effect is accelerated granulation tissue formation and enhanced healing process $[51,60,61]$.

Systemically administered, gentamicin may be toxic $[7,62]$. However, locally administered, the serum concentrations remain well below toxic levels [7,53,62]. The pathogens involved in SSIs after cardiac surgery is mainly coagulase-negative staphylococci (Staph Epidermidis) and Staph aureus, especially in deep infections $[4,7,29]$. Gentamicin has good activity on these organisms $[7,53]$.

The bactericidal effect of aminoglycosides is dependent on the peak level, and a high peak level is associated with a high bactericidal effect $[51,63,64]$. The minimum inhibitory concentration (MIC) of gentamicin for systemic antibiotic therapy is $4 \mathrm{mg} / \mathrm{L}$. Leyh et al. showed that with GCCI high local gentamicin levels (>300 mg/L) for $36 \mathrm{~h}$ are detected in mediastinal effusions [50]. Serum concentrations remain low (1-4 mg/L $1 \mathrm{~h}$ postoperatively and $\geq 1.5 \mathrm{mg} / \mathrm{L}$ after $24 \mathrm{~h}$ ). These values are well below the toxic threshold $(10 \mathrm{mg} / \mathrm{L})[51,53]$.

Therefore, a high bactericidal concentration of gentamicin in the anterior mediastinum and sternal bone can be anticipated. Besides, resistance is not an absolute feature of bacteria, but it results from the relation of growth inhibitory concentration of the bacteria to inhibitory concentration in the tissue. Grimm et al. demonstrated that bacteria which are resistant at the minimal inhibitory concentration (MIC) level are sensitive to higher gentamicin levels [65]. The peak local levels of gentamicin with GCCI are 75-200 times higher than the MIC making it highly effective against even resistant isolates [51]. In the study of Leyh et al., high bactericidal gentamicin levels were detected for $36 \mathrm{~h}$ after surgery [51]. It is uncertain how long gentamicin remains in mediastinal tissues, but release is dependent on the local blood flow [51].

Gentamicin kills bacteria by inhibiting protein synthesis and destabilizes bilayered membranes of bacteria [7]. Thus, each component of collagenous gentamycin may be effective, whereby gentamicin acts as a bactericidal agent and the carrier substance collagen possibly supports the wound healing process and bone regeneration $[7,51]$.

Initially concerns were raised that introduction of a topical antibiotic prophylaxis could induce antibiotic resistance with subsequent reduced effect of the prophylaxis [33]. However, pharmacokinetics of topical use of Collatamp shows an early high peak in the local gentamicin concentration, low serum concentrations and then rapid disappearance of the drug which reduces the selection of resistant bacteria. This pharmacokinetic profile is even favourable compared to normal IV use $[2,10]$.

\section{Use of collatamp in cardiac surgery}

Collatamp is available in 3 different presentations: $5 \mathrm{~cm} \times 5 \mathrm{~cm} ; 10 \mathrm{~cm} \times 10 \mathrm{~cm}$ and $5 \mathrm{~cm} \times 20 \mathrm{~cm}$ sizes [66]. Collatamp ${ }^{\ominus}$ implants are wrapped around the sternal edges prior to wound closure to ensure maximal concentration of gentamicin on all sides of the wound and inside the bone marrow. Sternal wires are used along the length of the sternum to firmly close the wound. Though collagen is rapidly resorbed, earlier it was argued that placing the collagen sponges between the sternal halves, rather than behind the sternum, might affect the sternal healing. Friberg et al. did not identify any such adverse effect $[2,10,33,44]$. However, the authors have emphasised the importance of a rigid fixation (defined as at least seven single sternal fixation wires), with complete compression of the sponges], to achieve a maximal reduction in deep infections by the collagen-gentamicin implant [44]. Too thick layer of Collatamp should be avoided as it can promote sternal instability [28].

Collatamp strips can also be used in vein harvesting site closure. Collatamp can be cut to size to fit the area to be treated. For SVG (Saphenous Vein Graft) harvesting site, once the vein has been removed, one $5 \times 20 \mathrm{~cm}$ Collatamp implant can be folded and packed into the open wound. The wound is then closed with sutures.

However, the patient's body weight and the total amount of gentamicin should be taken into account. 
When using for both sternotomy and vein harvest site closure the number and size of the implants should be selected so that a total dose of $9 \mathrm{mg}$ gentamicin sulphate per $\mathrm{kg}$ body weight is not exceeded [66]. Collatamp ${ }^{\circ}$ should be stored between $4^{\circ} \mathrm{C}$ and $25^{\circ} \mathrm{C}$ [66].

\section{Cautions and contraindications}

Collatamp $^{\oplus}$ is approved for commercial use within the European Union. No evidence of allergic reactions or adverse local effects on sternal healing has been reported [2]. In one study a higher incidence of early reoperation for bleeding in the Collatamp group was reported [2]. No side effects have been reported to date [2,43,50,51]. If the recommended maximum dose is exceeded, gentamicinspecific side effects cannot be ruled out completely, especially in the case of renal failure [66].

Systemically effective therapeutic blood or plasma levels are not generally achieved with the use of Collatamp ${ }^{\circ}$. However, interactions related to gentamicin should be considered. Besides, in patients with impaired renal function, the benefits of Collatamp ${ }^{\circ}$ must be carefully considered $[2,10,12,66]$.

Collatamp should not be used if a protein allergy is known or intolerability towards gentamicin has been observed. No experience has been gained in use during pregnancy and breast-feeding [66]. For this reason, the indication should be strictly established during pregnancy and breast-feeding [66].

No interactions have been reported to date. If adjuvant systemic treatment with gentamicin, other aminoglycoside antibiotics or other ototoxic or nephrotoxic drugs is necessary, the cumulative effects should be taken into account. In general, the number and size of the sponges should be selected so that a total dose of $9 \mathrm{mg}$ gentamicin sulphate per $\mathrm{kg}$ body weight is not exceeded [66].

\section{Cost analysis}

DSWI are the most common cause of prolonged hospital stay and increased hospital costs [7,19-22,50,51]. For GCCI to become part of routine practice clinical effectiveness has to be matched with cost effectiveness [12]. The use of Collatamp as an adjunct to IV antibiotics was found to be cost saving step $[2,44]$. This was due to fewer wound infections and lower costs involved in subsequent treatment despite the cost of the implants $[2,44]$. This was particularly relevant for high-risk patients e.g. those with diabetes or BMI $>25 \mathrm{~kg} / \mathrm{m} 2$ [44]. CoNS infections have an insidious presentation. They are difficult to treat, requiring prolonged courses of antibiotics, often requiring extensive surgical debridement with the use of muscle flaps [2,67]. It results in consumption of substantial healthcare resources $[2,67]$.

Eklund et al. suggests that it would be economical to use gentamicin-collagen implants in every CABG patient, since the treatment of mediastinitis is extremely expensive $[7,50,51]$. Friberg et al. concluded that despite the high cost of the gentamicin impregnated sponges, the use of two sponges, in addition to intravenous antibiotic prophylaxis, was cost effective, resulting in both lower costs and fewer infections for all patients as well as for high risk patients $[2,44]$.

\section{Clinical effectiveness: literature review}

A wealth of literature is now available on GCCI and Collatamp ${ }^{\oplus}$. Friberg et al. (Table 1) published a large double blind RCT (LOGIP Trial) on the role of GCCI in cardiac surgery [2]. Sternal closure was performed by the senior members of the team i.e. the operating surgeon. This study demonstrated an overall relative risk reduction in SSI in the GCCI-treated patients compared to the control group. The GCCI group demonstrated reduced need for surgical revision (2.3\% vs. $4.0 \%)$ and postoperative IV antibiotic usage (11.6\% vs. 18.0\%) [2]. Use of GCCI was shown to be even more beneficial in preventing both SSWI and DSWI in high-risk patients. In obese patients the difference in DSWI did not attend statistical significance. No significant difference in postoperative renal function or 60 day mortality was found. There was also no indication of any increase in the occurrence of gentamicin-resistant isolates. An unexplained finding was the significantly higher rebleeding rate in the GCCI arm [2]. The authors suggested that the incidence of reoperation for bleeding in the GCCI group was similar to that seen in routine practice, and that the re-operation rate in the control group was lower than expected [2].

NICE guidelines 2008 acknowledged the role of GCCI in 'Prevention and treatment of surgical site infection' based on the LOGIP trial [15]. However, it emphasised the need for evaluation of the long-term effects on microbial resistance [15].

For the two centres enrolling patients in LOGIP Trial use of GCCI became a routine practice. As suggested by NICE guidelines, the authors re-evaluated their technique with a prospective non randomised study designed for comparison with the previous control group from the LOGIP trial [33] (Table 1). The highly significant risk reduction found in the previous trial at the same institute raised ethical concerns in randomizing patients again to control/placebo [33]. They also changed the surgical technique and use of at least seven single wires for sternal fixation was emphasized in the protocol of this second study (compared to 6-8 wires used at Surgeon's discretion in the LOGIP Trial) [2,33]. The incidences of both superficial and deep SWI were less than half of that in the control group. The incidence of SWI was slightly lower than that in the treatment group of the primary LOGIP trial (4.3\% SWI with $2.3 \%$ deep SWI) 
Table 1 A summary of important studies on the use of GCCI (Gentamycin Containing Collagen Implants) in cardiac surgery

\begin{tabular}{lll}
\hline Authors & $\begin{array}{l}\text { Study design, } \mathbf{n}=\text { Number of } \\
\text { Subjects }\end{array}$ & Treatment groups \\
\hline Friberg O et al. [2], & $\begin{array}{l}\text { Double blind, Randomized, controlled, } \\
\text { two-centre study. Patients undergoing }\end{array}$ \\
$\begin{array}{ll}\text { cardiac surgery through median } \\
\text { sternotomy - including operations in }\end{array}$ & $\begin{array}{l}\text { Treatment } \mathrm{Gr}(\mathrm{Gr} \text { I): Collatamp } \\
\text { between the Sternal edges } \\
\text { the ascending aorta. }\end{array}$ \\
& & $\begin{array}{l}\mathrm{n}=983) \\
\text { Control } \mathrm{Gr}(\mathrm{Gr} \text { II): Standard } \\
\text { closure }(\mathrm{n}=967)\end{array}$ \\
& $\mathrm{N}=1950$ & $\begin{array}{l}\text { Standard antibiotic prophylaxis } \\
\text { given to both groups }\end{array}$ \\
& Evaluation: Double blind, ITT &
\end{tabular}

Friberg $\mathrm{O}$ et al. [33], 2009

[3], 2009

$\begin{array}{ll} & \text { (Control Gr from LOGIP Trial) } \\ \text { Eklund et al. } & \text { Randomised, Controlled Trial, } \\ {[7], 2005} & \text { Single-centre study. }\end{array}$

Evaluation: Partially Blinded

Schersten et al. [28], 2007

Leyh et al.

[51], 1999

\section{Observational Study}

(No Control Group) Impact of GCCl on treatment of DSWI, to assess side effects of Gentamycin topical use, and Gentamycin

level in mediastinal fluid

Bennett-Guerrero et al. Randomised, Controlled Trial, [67], 2010 $\mathrm{n}=2326$ total patients

Treatment $\mathrm{Gr}(\mathrm{Gr} \mathrm{I}): \mathrm{n}=1359$

Control Gr (Gr II): n = 967

Standard antibiotic prophylaxis given to both groups

$\mathrm{n}=542$ total patients

Treatment Gr (Gr I): $\mathrm{n}=272$

Control Gr (Gr II):

$\mathrm{n}=270$

Standard antibiotic prophylaxis given to both groups. Any patient staying in hospital for $>72$ hrs received IV Vancomycin in addition to routine IV Cefuroxime.

$\mathrm{n}=2026$ total patients

Treatment Gr (Gr I): n = 1091

Control Gr (Gr II):

$n=935$

Standard antibiotic prophylaxis given to both groups

$N=42$ Patients of DSWI after cardiac surgery were treated with Collatamp with or without other surgical interventions

\section{$\mathrm{n}=1502$ total patients}

Patients with diabetes $\mathrm{n}=1006[67 \%]$

Multicentre study

Patients undergoing cardiac surgery and at high-risk for sternal wound infection (diabetes, BMI $>30$ or both)
Patients with $\mathrm{BMI}>30$,

$\mathrm{n}=1137[76 \%]$

Treatment Gr (Gr I): $\mathrm{n}=753$

Control Gr (Gr II):

$\mathrm{n}=749$

\section{Results}

Wound infection ( $<2$ months post-operatively):

Group I vs Group || 4.3\% vs 9.0\% (RR 0.47; $p<0.001)$

Early reoperation for bleeding was more common in the treatment group (4.0\% vs $2.3 \%, p=0.03$ ).

Need for postoperative antibiotic treatment: Group I: $11.6 \%$ vs Group II: 18.0\% (RR 0.64: $p<0.001$ )

Wound infection ( $<60$ days postoperative):

Group I vs Gr II 3.7\% vs 9.0\% p $<0.001$

Surgical revision: Group I vs Group II $1.8 \%$ vs $3.9 \%(p<0.001)$

Wound infection ( $<3$ months post-operatively):

Group I vs Group II 4.0\% vs. 5.9\% ( $p=$ n.s.)

Incidence of mediastinitis: 1.1\% vs $1.9 \%$ $(P$ value $=N S)$

Wound infection (mediastinitis): Group I vs Group II

$0.75 \%$ vs $1.9 \%$

$(p<0.05)$

No definite conclusion regarding direct benefit of Collatamp use can be drawn from this study.

High (bactericidal) local levels of Gentamycin noted in mediastinal fluid

Wound infection ( $<90$ days post-operatively):

Incidence of all types of wound infection Group I Vs Gr II 8.4\% vs 8.7\% ( $\mathrm{p}$ value = n.s.)

Incidence of DSWI Group I: 1.9\% vs. 2.5\% $(p$ value $=$ n.s. $)$ 
Table 1 A summary of important studies on the use of GCCI (Gentamycin Containing Collagen Implants) in cardiac surgery (Continued)

\begin{tabular}{|c|c|c|c|}
\hline & & $\begin{array}{l}\text { Standard antibiotic prophylaxis } \\
\text { given to both groups }\end{array}$ & \\
\hline & & & $\begin{array}{l}\text { Incidence of SSWI Group I: } 6.5 \% \text { vs. } 6.1 \% \\
(p \text { value }=\text { n.s. })\end{array}$ \\
\hline & & & $\begin{array}{l}\text { Re-hospitalisation for sternal wound } \\
\text { infection (<90 days post-operatively): } \\
\text { Group I: } 3.1 \% \text { vs } 3.2 \% \text { ( } p \text { value = n.s.) }\end{array}$ \\
\hline \multirow[t]{7}{*}{$\begin{array}{l}\text { Birgand et al. } \\
\text { [68], } 2013\end{array}$} & $\begin{array}{l}\text { Quasi-experimental prospective } \\
\text { study (single-centre) }\end{array}$ & $\begin{array}{l}\mathrm{n}=552 \text { total patients } \\
\text { Intervention period }\end{array}$ & DSWI incidence rate: Intervention period \\
\hline & \multirow{6}{*}{$\begin{array}{l}\text { Diabetic and/or overweight } \\
\text { patients undergoing CABG with } \\
\text { bilateral internal mammary artery } \\
\text { grafts. }\end{array}$} & $\begin{array}{l}\text { patients managed with GCCl } \\
\mathrm{n}=175\end{array}$ & patients managed with GCCl: $12.6 \%$ \\
\hline & & $\begin{array}{l}\text { Intervention period patients } \\
\text { managed without } \mathrm{GCCl} n=88\end{array}$ & $\begin{array}{l}\text { Intervention period patients managed } \\
\text { without GCCl: } 6.8 \%\end{array}$ \\
\hline & & $\begin{array}{l}\text { Retrospective Control Gr, } \\
\text { preintervention era group } n=289\end{array}$ & $\begin{array}{l}\text { Retrospective Control Gr, preintervention } \\
\text { era group: } 13.8 \%\end{array}$ \\
\hline & & & $\begin{array}{l}\text { No statistically significant differences } \\
\text { between three groups. }\end{array}$ \\
\hline & & & $\begin{array}{l}\text { The group managed with the } \\
\text { sponge had a higher proportion } \\
\text { of gentamicin-resistant micro-organisms. }\end{array}$ \\
\hline & & $\begin{array}{l}\text { The end-point was the rate of } \\
\text { reoperation for deep sternal } \\
\text { wound infection. }\end{array}$ & \\
\hline \multirow{4}{*}{$\begin{array}{l}\text { Cohen et al. } \\
\text { [73], } 2010\end{array}$} & \multirow[t]{4}{*}{ Retrospective Case series } & $\mathrm{n}=216$ total patients & \multirow{4}{*}{$\begin{array}{l}\text { Wound infection: Group I vs Gr II: 0.0\% } \\
\text { vs 9.0\% ( } p \text { value }=0.0220)\end{array}$} \\
\hline & & Treatment Gr (Gr I): n = 108 & \\
\hline & & Control Gr (Gr II): & \\
\hline & & $n=108$ & \\
\hline \multirow{5}{*}{$\begin{array}{l}\text { Raja et al. } \\
\text { [50], } 2011\end{array}$} & Patient case series & $\mathrm{n}=194$ total patients & \multirow{5}{*}{$\begin{array}{l}\text { Wound infection: Incidence of SSWI } \\
\text { Group I vs Gr II: } 2.1 \% \text { vs } 6.2 \% \\
\text { ( } p \text { value }=0.01 \text {. Incidence of DSWI } \\
\text { Group I vs Gr II: } 2.1 \% \text { vs } 3.1 \% \text { ( } p \text { value }=\text { n.s) }\end{array}$} \\
\hline & \multirow{4}{*}{$\begin{array}{l}\text { Patients undergoing cardiac } \\
\text { surgery via sternotomy }\end{array}$} & Treatment $\mathrm{Gr}(\mathrm{Gr} \mathrm{I}): \mathrm{n}=97$ & \\
\hline & & Control Gr (Gr II): & \\
\hline & & $\mathrm{n}=97$ & \\
\hline & & $\begin{array}{l}\text { Standard antibiotic prophylaxis } \\
\text { given to both groups }\end{array}$ & \\
\hline \multirow{9}{*}{$\begin{array}{l}\text { Schimmer et al. } \\
\text { [74], } 2012\end{array}$} & \multirow{2}{*}{$\begin{array}{l}\text { Randomised, Controlled Trial, } \\
\text { Double blind }\end{array}$} & $\mathrm{n}=723$ total patients & Wound infection ( $<30$ days): \\
\hline & & \multirow{5}{*}{$\begin{array}{l}\text { Treatment Gr (Grl) GCCl Gr, } \\
\text { Collagen Implant with } \\
\text { Gentamycin: } \mathrm{n}=354\end{array}$} & Incidence of SSWI/DSWI \\
\hline & \multirow{4}{*}{ Single-centre study } & & (Group I vs Gr II) \\
\hline & & & $0.56 \% / 1.9 \%$ vs \\
\hline & & & $3.52 \% / 2.9 \%$ \\
\hline & & & $(p=0.013)$ \\
\hline & \multirow[t]{3}{*}{$\begin{array}{l}\text { Comparison of a } \mathrm{GCCl} \text { versus } \\
\text { a simple Collagen sponge }\end{array}$} & $\begin{array}{l}\text { Control Gr (Gr II) Simple } \\
\text { collagen implant without } \\
\text { Gentamycin: }\end{array}$ & \\
\hline & & $n=369$ & \\
\hline & & $\begin{array}{l}\text { Standard antibiotic prophylaxis } \\
\text { given to both groups }\end{array}$ & \\
\hline $\begin{array}{l}\text { Creanor et al. } \\
{[12], 2012}\end{array}$ & $\begin{array}{l}\text { Meta-analysis of randomised } \\
\text { controlled trials }\end{array}$ & $\begin{array}{l}\text { Three randomised controlled } \\
\text { trials (published between } 2005 \\
\text { and 2010) involving 3,994 patients }\end{array}$ & $\begin{array}{l}\text { There is insufficient evidence of the } \\
\text { effectiveness (or otherwise) of GCCl in } \\
\text { preventing SWls following cardiac surgery. } \\
\text { However, some evidence does exist that } \\
\text { such sponges can reduce the incidence } \\
\text { of deep infections in high risk patients }\end{array}$ \\
\hline
\end{tabular}


Table 1 A summary of important studies on the use of GCCI (Gentamycin Containing Collagen Implants) in cardiac surgery (Continued)

Chang et al.

[75], 2013
Systematic Review and Meta-analysis

of Randomized Trials
Fifteen randomised controlled trials involving 6979 patients
Use of $\mathrm{GClCl}$ was associated with a significant decrease in SSI with an NNT of $21 \mathrm{p}=0.001$;

Post hoc analysis showed that $\mathrm{GCCl}$ implants are effective in reducing SSI in sternotomy wounds. $(\mathrm{OR}=0.59 ; 95 \% \mathrm{Cl}: 0.37-0.96 ;)(\mathrm{P}=0.03 ; \mathrm{NNT}=32)$

GCCl reduced the risk of DSWI and need for surgical revision. No impact on SSWI or all cause mortality. Most commonly isolated pathogens were CoNS.

\author{
Treatment Group = GCCI Group. \\ $\mathrm{RCT}=$ Randomised Controlled Trial \\ NNT $=$ Numbers Needed to Treat. \\ SSWI = Superficial Sternal Wound Infection. \\ DSWI = Deep Sternal Wound Infection. \\ SSI = Surgical Site Infection. \\ SWI = Sternal Wound Infection. \\ CoNS = Coagulase Negative Staphylococcus Aureus \\ CABG $=$ Coronary Artery Bypass Graft. \\ $\mathrm{BMI}=$ Body Mass Index. \\ $\mathrm{RR}=$ Relative Risk. \\ $\mathrm{OR}=$ Odds Ratio. \\ $\mathrm{Cl}=$ Confidence Interval.
}

probably due to improvement in surgical technique. However, it is not possible to differentiate the relative effects of each of the variables (improvement in surgical technique and impact of GCCI) in improvement of sternal wound complications [33].

No trend towards less effect over time could be detected after 7 years of daily use [2,33]. A microbiological analysis between the two studies after a gap of several years showed that there had been no change in types of causative bacteria and no absolute increase in SSIs caused by aminoglycoside resistant microbes over time $[2,33]$. The organisms isolated were predominantly CoNS. They were resistant to both aminoglycosides and methicillin in approximately $80 \%$ of cases. These 'resistant' strains may be susceptible to the extremely high local concentrations achieved with GCCI [33].

Eklund et al. performed a RCT which did not show any evidence of beneficial effect of GCCI in prevention of sternal wound infection [7] (Table 1). However, the authors emphasised that with the infection rates in their study (4\% study group; $5.9 \%$ control group), the sample size necessary to detect a significant $(P<0.05) \mathrm{RR}$ with a statistical power of 0.8 would be 1275 patients in each group. The authors acknowledged that the study was too small to draw any firm conclusions (total 542 patients with 272 and 270 patients in each group).

Schersten et al. reported that after adding GCCI to their standard treatment protocol in a consecutive and unselected series of 1091 patients, they noticed a significant drop in the rate of mediastinitis [28] (Table 1). However, in this series of patients they made a significant change in their sternal closure technique (emphasis on more than 7 sternal wires for all patients) and it was difficult to discern the impact of GCCI alone in bringing down the rate of mediastinitis [28].

Leyh et al. treated mediastinitis with sternum refixation and gentamicin-collagen sponge successfully in 42 patients [51] (Table 1). The study was designed for effectiveness of measures to treat DSWI and not for prevention. Use of Collatamp resulted in high mediastinal fluid level of Gentamicin which will be bactericidal for even Gentamicin resistant strains (15\% organisms were Gentamicin resistant in this study) [51]. However, as all patients were treated with multiple interventions, no definite conclusion can be drawn from this study regarding direct beneficial effect of GCCI use in treatment of DSWI [51].

Bennett-Guerrero conducted a multicenter RCT of 1502 patients in US for patients undergoing cardiac surgery and at high-risk for sternal wound infection (diabetes, BMI $>30$ or both) [67] (Table 1). No significant difference was noted in the rates of SSWI or DSWI or rehospitalisation rate for wound infection up to 90 days after surgery [67]. Similarly, Birgand et al. conducted a quasi-experimental single-centre prospective study in diabetic and/or overweight patients undergoing coronaryartery bypass surgery with bilateral internal mammary artery grafts [68] (Table 1). They found no evidence of efficacy of GCCI [68]. Interestingly in both these studies GCCI were soaked in saline prior to use $[67,68]$.

Corn $\mathrm{T}$ et al., Raja et al. and Friberg $\mathrm{O}$ et al. challenged the findings of these studies which were in contrast to the findings of several other contemporary studies [68-70]. The study protocol and the training video of the study by Bennett-Guerrero et al. describes dipping GCCI for 1-2 sec in saline prior to use [69-71]. The GCCI used in this trial is marketed by EUSA Pharma (Europe) which 
in their product information clearly states that the product should be used dry $[66,69]$. Gentamicin sulfate is highly soluble in aqueous solutions and dipping it in saline prior to use alters the release characteristics of Gentamicin decreasing its efficacy $[66,69]$.

Lovering et al. conducted a study evaluating the impact of soaking gentamicin- containing collagen implants on potential antimicrobial efficacy of GCCI [72]. The study showed that even a short period of dipping of gentamicincollagen sponge, before insertion into the patient, results in a significant loss of gentamicin [72]. The mean loss of Gentamicin was $6.7 \%$ at $2 \mathrm{~s}$, increasing to $40.5 \%$ at $1 \mathrm{~min}$ and essentially total loss by $6 \mathrm{~h}$ of immersion [72]. This study provides clinching evidence that even a short period of dipping of Collatamp implants, before insertion into the patient results in a significant loss of gentamicin which may be of clinical significance [72].

In a retrospective review Cohen and colleagues compared a group of 108 patients who had received GCCI to a group of matched contemporary controls on a 1:1 basis [73] (Table 1). There was a significant difference in the incidence of post-operative SSI between the two groups ( $0 \%$ GCCI vs. 9\% standard treatment; $\mathrm{p}$ value 0.022 ). Raja and colleagues conducted a propensity score analysis and compared the adjunctive use of GCCI in patients deemed at high risk of developing SSI to a group of matched controls [50] (Table 1). This study demonstrated a significant benefit of GCCI, which reduced the rate of superficial wound infection by $66 \%$ compared to standard treatment alone (2.1\% GCCI vs. 6.2\% standard treatment; p value 0.01) [50]. Although the patients in the GCCI group also had a lower rate of deep wound infection compared to the control group, this difference did not reach statistical significance [50].

Most of these studies compared GCCI versus routine antibiotic prophylaxis and suffered from a limitation as there were no control arms for Collagen sponge without Gentamycin. Schimmer et al. addressed this issue with a double blind RCT Comparison of a GCCI versus a simple Collagen sponge [74] (Table 1). The two types of sponges were implanted retrosternally in dry condition. This study has shown a significant reduction in DSWI and SSWI in patients undergoing median sternotomy for cardiac surgery with routinely application of a GCCI. Numbers needed to treat (NNT) for all sternal wound infections and deep sternal wound infections were 26 and 33, respectively [74].

Multiple randomized controlled trials (RCTs) produced conflicting results [74]. Creanor et al. performed a meta analysis of three randomised controlled trials (published between 2005 and 2010) involving 3,994 participants [12] (Table 1). Using random effects models, odds ratios (OR) and corresponding 95\% confidence intervals (CI) were calculated for all SWIs and deep SWIs. There was insufficient evidence of the effectiveness (or otherwise) of gentamicin impregnated sponges in preventing SWIs following cardiac surgery. However, some evidence does exist that such sponges can reduce the incidence of deep infections in high risk patients. Chang et al. therefore conducted a systematic review and meta-analysis of all relevant RCTs [75] (Table 1). Fifteen RCTs encompassing a total of 6979 patients were included. The included studies were of moderate to high quality. Gentamicincollagen implants significantly reduced SSI $[\mathrm{OR}=0.51$; 95\% CI: 0.33-0.77; $P=0.001$ [75].

Mavros et al. performed a meta-analysis of randomized controlled trials [76] (Table 1). Four RCTs were considered of high quality (score of 3 or more according to modified Jadad criteria) and were included in the study (4672 patients). GCCI reduced risk of DSWI (risk ratio, 0.62; 95\% confidence interval, 0.39-0.97). However, no benefit was demonstrated regarding superficial sternal wound infections and all-cause mortality [76]. Pooled data from 2 randomized controlled trials (3410 patients), showed that use of GCCI also reduced the need for surgical revision of sternal wounds (risk ratio, 0.59; 95\% confidence interval, 0.41-0.86). The most commonly isolated pathogens were coagulase-negative Staphylococcus spp (43\%) and Staphylococcus aureus (28\%) [76]. The authors concluded that there is large statistical heterogeneity among the existing trials and emphasised the need for additional large, high-quality randomized controlled trials [76].

Popescu et al. did a retrospective audit of 2238 patients where Collatamp was used in only 122 patients (5\%) [77]. The rate of sternal wound infection in non-Collatamp group was $3 \%$ while it was $5 \%$ in Collatamp group [77]. The length of stay in hospital was shorter in Collatamp patients. No gentamicin sensitivity was recorded within the Collatamp group. Because of the small numbers and retrospective nature of the study no definite conclusion could be drawn [77].

It should be noted that in cardiothoracic surgery, where the infection rate is low, it is difficult to perform studies with appropriate statistical power. Eklund et al. highlighted that with the infection rates in their study (4\% study group; $5.9 \%$ control group), the sample size necessary to detect a significant $(P<0.05) \mathrm{RR}$ with a statistical power of 0.8 would be 1275 patients in each group [7]. As a result several studies are small, inadequately powered and it's difficult to draw firm conclusions from such studies.

\section{Conclusion}

Safety and efficacy of GCCI (Collatamp) has been debated and tested in several recent studies with conflicting results. Several recent studies have supported their clinical effectiveness. They should be 
not be soaked in saline even for a short period prior to use.

Based on the evidence presented in this manuscript, it is recommended GCCI (Collatamp) can be a cost effective adjunct for prevention of sternal wound infection. They can also be used for treatment of DSWI.

\section{Abbreviations}

SWI: Sternal wound infections; SSI: Surgical site infection; GCCl: Gentamicin containing collagen implants; SSWI: Superficial sternal wound infection; DSWI: Deep Sternal wound infection; NICE: National institute of clinical excellence; CoNS: Coagulase-negative staphylococci; MIC: Minimum inhibitory concentration; RCT: Randomized controlled trials.

\section{Competing interests}

The authors declare that they have no competing interests.

\section{Authors' contributions}

PKM: Literature search, preparation of the manuscript, revising the manuscript, submission, corresponding author. AA: Literature search, preparing the manuscript. KS: Literature search, preparation of the manuscript, DA: Literature search, preparation of the manuscript; SO: Literature search, preparation of the manuscript, Revising the manuscript; SGR: Literature search, preparation of the manuscript. HL: Literature search, preparation of the manuscript, revising the manuscript. All authors read and approved the final manuscript.

\section{Funding}

No funding was received for conduct of the study. After acceptance of the manuscript by the publishers, EUSA Pharma funded the publication charges mandatory for Biomedcentral.

\section{Author details}

'Cardiothoracic Unit, Heart and Lung Centre, Wednesfield Road, Wolverhampton WV10 0QP, UK. ${ }^{2}$ Wessex Cardiothoracic Centre, Tremona Road, Southampton SO16 6Y, UK. ${ }^{3}$ Harefield Hospital, Hill End Road, London UB9 6JH, UK

Received: 8 March 2014 Accepted: 28 May 2014

Published: 8 July 2014

\section{References}

1. Godbole G, Pai V, Kolvekar S, Wilson A: Use of gentamicin-collagen sponges in closure of sternal wounds in cardiothoracic surgery to reduce wound infections. Interact Cardiovasc Thorac Surg 2012

14(4):390-394. April.

2. Friberg O, Svedjeholm R, Soderquist B, Granfeldt H, Vikerfors T, Kallman J: Local gentamicin reduces sternal wound infections after cardiac surgery: a randomized controlled trial. Ann Thorac Surg 2005, 79:153-161.

3. Mossad SB, Serkey JM, Longworth DL, Cosgrove DM, Gordon SM: Coagulase-negative staphylococcal sternal wound infections after open heart operations. Ann Thorac Surg 1997, 63:395-401.

4. Tegnell A, Aren C, Ohman L: Coagulase-negative staphylococci and sternal infections after cardiac operation. Ann Thorac Surg 2000, 69:1104-1109

5. Hall RE, Ash AS, Ghali WA, Moskowitz MA: Hospital cost of complications associated with coronary artery bypass graft surgery. Am J Cardiol 1997, 79:1680-1682

6. Taylor GJ, Mikell FL, Moses HW, et al: Determinants of hospital charges for coronary artery bypass surgery: the economic consequences of postoperative complications. Am J Cardiol 1990, 65:309-313.

7. Eklund AM, Valtonen M, Werkkala KA: Prophylaxis of sternal wound infections with gentamicin-collagen implant: randomized control study in cardiac surgery. J Hosp Infect 2005, 59:108-112.

8. Stemberger A, Grimm H, Bader F, Rahn HD, Ascherl R: Local treatment of bone and soft tissue infections with the collagen-gentamicin sponge. Eur J Surg 1997, 578(Suppl):17-26.

9. Rutten HJ, Nijhuis PH: Prevention of wound infection in elective colorectal surgery by local application of a gentamicin-containing collagen sponge. Eur J Surg 1997, 578(Suppl):31-35.
10. Friberg O, Jones I, Sjoberg L, Soderquist B, Vikerfors T, Kallman J: Antibiotic concentrations in serum and wound fluid after local gentamicin or intravenous dicloxacillin prophylaxis in cardiac surgery. Scand I Infect Dis 2003, 35:251-254

11. Karlowsky JA, Jones ME, Draghi DC, Thornsberry C, Sahm DF, Volturo GA Prevalence and antimicrobial susceptibilities of bacteria isolated from blood cultures of hospitalized patients in the United States in 2002. Ann Clin Microbiol Antimicrob 2004, 3:7.

12. Creanor S, Barton A, Marchbank A: Effectiveness of a gentamicin impregnated collagen sponge on reducing sternal wound infections following cardiac surgery: a meta-analysis of randomised controlled trials. Ann R Coll Surg Engl 2012, 94(4):227-231(5).

13. Mangram AJ, Horan TC, Pearson ML, Silver LC, Jarvis WR: Guideline for prevention of surgical site infection, 1999 (Hospital Infection Control Practices Advisory Committee). Infect Control Hosp Epidemiol 1999, 20:250-278.

14. CDC/NHSN surveillance definition of health care-associated infection and criteria for specific types of infections in the acute care setting. Am J Infect Control 2008, 36(5):309-332. doi: 10.1016/j.ajic.2008.03.002.

15. Surgical site infection: full guideline. National Institute for Health and Clinical Excellence. 2008, SBN 978-1-904752-69-1. (Updated 2013) https://www.evidence.nhs.uk/evidence-update-43 http://www.nice.org.uk/ nicemedia/pdf/CG74FullGuideline.pdf.

16. Wilson AP, Treasure T, Sturridge MF, Gruneberg RN: A scoring method (ASEPSIS) for postoperative wound infections for use in clinical trials of antibiotic prophylaxis. Lancet 1986, 1:311-313.

17. Luckraz H, Treasure T: Infections in cardiac surgery. Surg Infect 1996, 4:1-4.

18. Franco $S$, Herrera AM, Atehortúa M, Vélez L, Botero J, Jaramillo JS, Vélez JF, Fernández $\mathrm{H}$ : Use of steel bands in sternotomy closure: implications in high-risk cardiac surgical population. Interact Cardiovasc Thorac Surg 2009, 8(2):200-5. doi: 10.1510/icvts.2008.188136. Epub 2008 Nov 27.

19. DiPiro JT, Martindale RG, Bakst A, Vacani PF, Watson P, Miller MT: Infection in surgical patients: effects on mortality, hospitalization, and post discharge care. Am J Health Syst Pharm 1998, 55:777-781.

20. Higgins TL, Estafanous FG, Loop FD, Beck GJ, Blum JM, Paranandi L: Stratification of morbidity and mortality outcome by preoperative risk factors in coronary artery bypass patients. JAMA 1992, 267:2344-2348.

21. Farinas MC, Gald Peralta F, Bernal JM, Revuelta JM, Gonzalez-Macias J: Suppurative mediastinitis after open-heart surgery: a case-control study covering a seven-year period in Santander, Spain. Clin Infect Dis 1995, 20:272-279

22. Valla J, Corbineau H, Langanay $T$, et al: Mediastinitis after cardiac surgery. A 10-year evaluation (1985-1995). Ann Cardiol Angeiol 1996, 45:369-376.

23. Luckraz H, Murphy F, Bryant S, Charman SC, Ritchie AJ: Vacuum-assisted closure as a treatment modality for infections after cardiac surgery. J Thorac Cardiovasc Surg 2003, 125(2):301-305. Feb.

24. Horan TC, Gaynes RP, Martone WJ, Jarvis WR, Emori GT: CDC definitions of nosocomial surgical site infections. Infect Control Hosp Epidemiol 1992, 13:606-608

25. Ottino G, De Paulis R, Pansini $S$, et al: Major sternal wound infection after open-heart surgery: a multivariate analysis of risk factors in 2,579 consecutive operative procedures. Ann Thorac Surg 1987, 44:173-179.

26. Bitkover CY, Gårdlund B: Mediastinitis after cardiovascular operations: a case-control study of risk factors. Ann Thorac Surg 1998, 65:36-40.

27. Kreter B, Woods M: Antibiotic prophylaxis for cardiothoracic operations: Meta-analysis of thirty years of clinical trials. J Thorac Cardiovasc Surg 1992, 104:590-599.

28. Schersten $\mathrm{H}$ : Modified prophylaxis for preventing deep sternal wound infection after cardiac surgery. APMIS 2007, 11:1025-1028.

29. The Parisian Mediastinitis Study Group: Risk factors for deep sternal wound infection after sternotomy: a prospective, multicenter study. J Thorac Cardiovasc Surg 1996, 11:1200-1207.

30. Hashimoto I, Takaku M, Matsuo S, Abe Y, Harada H, Nagae H, Fujioka Y, Anraku K, Inagawa K, Nakanishi H: Risk factors for complications after reconstructive surgery for sternal wound infection. Arch Plast Surg 2014, 41(3):253-257. doi: 10.5999/aps.2014.41.3.253. Epub 2014 May 12.

31. Hammermeister KE, Burchfiel CR, Grover FL: Identification of patients at greatest risk for developing major complications at cardiac surgery. Circulation 1990, 82(Suppl. 5):IV380-IV389.

32. Milano CA, Kesler K, Archibald N, Sexton DJ, Jones RH: Mediastinitis after coronary artery bypass graft surgery. Circulation 1995, 92:2245-2251. 
33. Friberg O, Dahlin LG, Kallman J, Kihlstrom E, Soderquist B, Svedjeholm R: Collagen-gentamicin implant for prevention of sternal wound infection; long-term follow-up of effectiveness. Interact Cardivasc Thorac Surg 2009, 9:454-458.

34. Friedrich B, Klaue P, Worlock P, Slack R, Harvey L, Mawhinney R, Koury M, Ellis $E$ 3rd: Mechanical stability and post-traumatic osteitis: an experimental evaluation of the relation between infection of bone and internal fixation. Injuny 1977, 9:23-29.

35. Stahle E, Tammelin A, Bergstrom R, Hambreus A, Nystrom SO, Hansson HE: Sternal wound complications-incidence, microbiology and risk factors. Eur J Cardiothorac Surg 1997, 11:1146-1153.

36. Gardlund B, Bitkover CY, Vaage J: Postoperative mediastinitis in cardiac surgery - microbiology and pathogenesis. Eur J Cardiothorac Surg 2002, 21:825-830.

37. Wilson AP, Gruneberg RN, Treasure T, Sturridge MF: Staphylococcus epidermidis as a cause of postoperative wound infection after cardiac surgery: assessment of pathogenicity by a wound-scoring method. $\mathrm{Br} J$ Surg 1988, 75:168-170.

38. Darouiche RO: Treatment of infections associated with surgical implants N Engl J Med 2004, 350:1422-1429.

39. Otto M: Molecular basis of Staphylococcus epidermidis infections. Semin Immunopathol 2012, 34:201-214.

40. Widerström M, Wiström J, Sjöstedt A, Monsen T: Coagulase-negative staphylococci: update on themolecular epidemiology and clinical presentation, with a focus on Staphylococcus epidermidis and Staphylococcus saprophyticus. Eur J Clin Microbiol Infect Dis 2012, 31:7-20.

41. Beckmann A, Doebler K, Schaefer E, Koetting J, Gastmeier P, Graf K: Sternal surgical site infection prevention - is there any room for improvement? Eur J Cardiothorac Surg 2011, 40:347-351.

42. Lador A, Nasir H, Mansur N, Sharoni E, Biderman P, Leibovici L, Paul M: Antibiotic prophylaxis in cardiac surgery: systematic review and meta-analysis. J Antimicrob Chemother 2012, 67:541-350.

43. Shahzad G: Raja. Local application of gentamicin-containing collagen implant in the prophylaxis and treatment of surgical site infection following cardiac surgery. Int J Surg 2012, 10:S10eS14.

44. Friberg Ö, Dahlin LG, Söderquist B, Källman J, Svedjeholm R: Influence of more than six sternal fixation wires on the incidence of deep sternal wound infection. Thorac Cardiovasc Surg 2006, 54:468-473.

45. Bratzler DW, Dellinger EP, Olsen KM, Perl TM, Auwaerter PG, Bolon MK, Fish DN, Napolitano LM, Sawyer RG, Slain D, Steinberg JP, Weinstein RA, American Society of Health-System Pharmacists; Infectious Disease Society of America; Surgical Infection Society; Society for Healthcare Epidemiology of America: Clinical practice guidelines for antimicrobial prophylaxis in surgery. Am J Health Syst Pharm 2013, 70(3):195-283. doi: 10.2146/ ajhp120568.

46. Song F, Glenny AM: Antimicrobial prophylaxis in colorectal surgery: a systematic review of randomized controlled trials. Br J Surg 1998, 85:1232e41.

47. Morita S, Nishisho I, Nomura T, Fukushima Y, Morimoto T, Hiraoka N, Shibata N: The significance of the intraoperative repeated dosing of antimicrobials for preventing surgical wound infection in colorectal surgery. Surg Today 2005, 35:732-8.

48. Suehiro T, Hirashita T, Araki S, Matsumata T, Tsutsumi S, Mochiki E, Kato H, Asao T, Kuwano H: Prolonged antibiotic prophylaxis longer than 24 hours does not decrease surgical site infection after elective gastric and colorectal surgery. Hepatogastroenterology 2008, 55:1636-9.

49. Jamil H-C: Gentamicin-ixmpregnated collagen sponge for high-risk cardiac surgery patients. Interact Cardiovasc Thorac Surg 2013, 16(2):141. (eComment) Feb.

50. Raja SG, Salhiyyah K, Rafiq MU, Felderhof J, Amrani M: Impact of gentamicin-collagen sponge (collatamp) on the incidence of sternal wound infection in high-risk cardiac surgery patients: a propensity score analysis. Heart Surg Forum. 2012, 15:e257-261.

51. Leyh RG, Bartels C, Sievers HH: Adjuvant treatment of deep sternal wound infection with collagenous gentamycin. Ann Thorac Surg. 1999, 68:1648-1651.

52. Rutten HJ, Nijhuis PH: Prevention of wound infection in elective colorectal surgery by local application of a gentamicin-containing collagen sponge. Eur J Surg Suppl. 1997, 578:31-35.

53. Stemberger A, Grimm H, Bader F, Rahn HD, Ascherl R: Local treatment of bone and soft tissue infections with the collagen-gentamicin sponge. Eur J Surg Suppl. 1997, 578:17-26.
54. Ruszczak Z, Friess W: Collagen as a carrier for on-site delivery of antibacterial drugs. Adv Drug Deliv Rev. 2003, 55:1679-1698.

55. Chvapil M: Collagen sponge: theory and practice of medical applications. J Biomed Mater Res 1977, 11:721-741.

56. Anderson RE, Lukas G, Skullman S, Hugander A: Local administration of antibiotics by gentamicin-collagen sponge does not improve wound healing or reduce recurrence rate after pilonidal excision with primary suture: a prospective randomized controlled trial. World J Surg 2010, 34:3042-3048

57. Buimer MG, Ankersmit MF, Wobbes T, Klinkenbijl JH: Surgical treatment of hidradenitis suppurativa with gentamicin sulfate: a prospective randomized study. Dermatol Surg 2008, 34:224-227.

58. Gruessner U, Clemens M, Pahlplatz PV, Sperling P, Witte J, Rosen HR, Septocoll Study Group: Improvement of perineal wound healing by local administration of gentamicin-impregnated collagen fleeces after abdominoperineal excision of rectal cancer. Am J Surg 2001, 182:502-509.

59. Yetim I, Ozkan O, Dervisoglu A, Erzurumlu K, Canbolant E: Effect of gentamicin-absorbed collagen in wound healing in pilonidal sinus surgery: a prospective randomized study. J IntMed Res 2010, 38:1029-1033.

60. Lorenzetti OJ, Fortenberry B, Busby E: Influence of microcrystalline collagen in wound healing. // Comparison of several collagen dressings on excised wounds of pigs and rabbits. Res Comm Chem Path Pharm. 1973, 5:431-440.

61. Reddi AH: Implant stimulated interface reaction during collagenous bone matrix induced bone formation. J Biomed Mater Res. 1985, 19:233-239.

62. Kadurugamuwa $\mathrm{L}$, Beveridge TJ: Natural release of virulence factors in membrane vesicles by Pseudomonas aeruginosaand the effect of aminoglycoside antibiotics on their release. J Antimicrob Chemother. 1997, 40:615-621.

63. Moore RD, Smith CR, Lietman PS: The association of aminoglycoside plasma levels with mortality in patients with gram negative bacteremia. J Infect Dis. 1984, 149:443-448.

64. Moore RD, Lietman PS, Smith CR: Clinical response to aminoglycoside therapy (importance of the ratio of peak concentration to minimal inhibitory concentration). J Infec Dis 1987, 155:93-99.

65. Grimm H: Collagen as a drug carrier and its application in surgery. 1st edition. Edited by Stemberger A, Ascherl R, Lechner F, Blümel G. Stuttgart, New York: Schattauer; 1989:33-37.

66. Collatamp. Product Information. http://www.eusapharma.com/en-gb/default. aspx, http://www.eusapharma.com/smpc/collatamp/en/SmPC-PortugalCronocol-English.pdf.

67. Bennett-Guerrero E, Ferguson TB Jr, Lin M, Garg J, Mark DB, Scavo VA Jr, Kouchoukos N, Richardson JB Jr, Pridgen RL, Corey GR, SWIPE-1 Trial Group: Effect of an implantable gentamicin-collagen sponge on sternal wound infections following cardiac surgery: a randomized trial. JAMA 2010, 304(307):755-62. Aug 18.

68. Birgand G, Radu C, Alkhoder S, Al Attar N, Raffoul R, Dilly MP, Nataf P, Lucet JC: Does a gentamicin-impregnated collagen sponge reduce sternal wound infections in high-risk cardiac surgery patients? Interact Cardiovasc Thorac Surg 2013, 16(2):134-141.

69. Corn T: Treating sternal wound infections after cardiac surgery with an implantable gentamicin-collagen sponge. Letter. J Am Med Assoc 2010, 304:2123. doi: 10.1001/jama.2010.1612.

70. Raja SG: The devil is in the detail! Interact Cardiovasc. Thorac Surg 2013, 16(2):141-142

71. Friberg O: Treating sternal wound infections after cardiac surgery with an implantable gentamicin-collagen sponge-letter. J Am Med Assoc 2010, 304:2123-4. doi: 10.1001/jama.2010.1613.

72. Lovering AM, Sunderland J: Impact of soaking gentamicin- containing collagen implants on potential antimicrobial efficacy. Int J Surg 2012, 10(Suppl 1):S2-4.

73. Cohen G, Fremes S, Sever J, Moussa GT, Christakis GT, Goldman BS: Mitigation of sternal wound infection by application of a gentamicin impregnated collagen sponge at the time of sternal closure. In: presented at the Canadian cardiovascular congress; 2010. [Abstract 495].

74. Schimmer C, Ozkur M, Sinha B, Hain J, Gorski A, Hager B, Leyh R: Gentamicin-collagen sponge reduces sternal wound complications after heart surgery: A controlled, prospectively randomized, double-blind study. J Thorac Cardiovasc Surg 2012, 143(194):194-200.

75. Chang WK, Srinivasa S, MacCormick AD, Hill AG: Gentamicin-collagen implants to reduce surgical site infection: systematic review and meta-analysis of randomized trials. Ann Surg 2013, 258(1):59-65. Jul. 
76. Mavros MN, Mitsikostas PK, Alexiou VG, Peppas G, Falagas ME: Gentamicin collagen sponges for the prevention of sternal wound infection: a meta-analysis of randomized controlled trials. J Thorac Cardiovasc Surg 2012, 144:1235-1240.

77. Popescu F, Rochon N, Raja S: Impact of Gentamicin - Collagen Sponge (Collatamp) on the incidence of sternal wound infection in high risk cardiac surgery patients. Journal of Cardiothoracic Surgery 2013, 8(Suppl 1):0123.

doi:10.1186/1749-8090-9-122

Cite this article as: Mishra et al:: Role of topical application of gentamicin containing collagen implants in cardiac surgery. Journal of Cardiothoracic Surgery 2014 9:122.

\section{Submit your next manuscript to BioMed Central and take full advantage of:}

- Convenient online submission

- Thorough peer review

- No space constraints or color figure charges

- Immediate publication on acceptance

- Inclusion in PubMed, CAS, Scopus and Google Scholar

- Research which is freely available for redistribution 